This PDF is a simplified version of the original article published in Internet Archaeology. All links also go to the online version.

Please cite this as: Kreiter, A. 2021 The Hungarian Archaeology Database , Internet Archaeology 58. https://doi.org/10.11141/ia.58.9

\title{
The Hungarian Archaeology Database
}

Attila Kreiter

\section{Summary}

In Hungary, certain site documents, such as the Preliminary Archaeological Documentation (PAD), 30-day report and 1-year report, have to be submitted to centralised institutions. The content and format of these documents are regulated, facilitating their digital archiving and accessibility. However, further documents (inventories, databases, scientific assessments, interdisciplinary analysis, photos, drawings, etc.), mainly created by the museum that carried out the excavation, may not end up in the designated repositories. Instead, these documents are stored in the local museums that carried out the excavations and/or where the finds are kept.

It is a major problem that there is no officially-appointed, centralised hard copy and/or digital repository in Hungary where all site documents are stored and made accessible. In this respect, there are millions of files stored in museums all over the country that are neither used nor reused and are not accessible, and without the archaeological community, or even central institutions, being aware of them. Another problem is that digital archiving of archaeological documents is not regulated either on a national or local level.

The only repository that includes both metadata and documents in Hungary is the Archaeology Database of the National Museum. This database provides a solution for depositing digital documents, and it could serve as a national repository where documents can be stored and accessed online in one place (through access levels). However, submitting digital documents to the archaeology database is unregulated and it is completely voluntary. The archaeology database has the potential to assist archiving on a national level should it become compulsory to submit documents to it, as its structure was designed in accordance with the protocols and it hosts documents. 


\section{Institutions and Legislation in Hungary}

According to the legal regulation of archaeological excavations in Hungary, only state or local government-owned institutions (museums, universities and other heritage institutions) are allowed to carry out excavations; private companies are excluded. Before each excavation project an institution that is entitled to undertake excavations has to apply to the local heritage authorities for an excavation permit (LXIV/2001 Cultural Heritage Act).

Excavations connected to developments are usually carried out by local museums. Only the Hungarian National Museum and the Castle Headquarters Ltd - as central heritage institutions - are permitted to excavate throughout the country. The Hungarian archaeological approach to preventive archaeology is essentially based on two major principles: 1) archaeological artefacts found in the ground are state property; 2) it is of public interest to protect and excavate archaeological heritage under threat - therefore everything has to be excavated and saved. The implementation of the Valletta Convention was undertaken in 2001 in Hungary and has been revised several times (149/2000 (VIII 31) Government Decree). The assessment of archaeological coverage prior to large developments was integrated into the planning process and the 'polluter pays' principle was a fundamental element of the legislation. The continuous price and time reduction regulations pushed Hungarian archaeology towards non-destructive site identification methods. Additionally, the increasing developer-focused approach has resulted in the appearance of predictive archaeological models offering effective tools to estimate archaeological costs.

The Castle Headquarters Ltd as a central state body provides developers with complex Preliminary Archaeological Documentation (PAD), which contains the identified cultural heritage elements, suggested action plans and financial calculations for archaeological tasks. In Hungary, it is mandatory to prepare a PAD for every construction above $\sim$ EUR 1.5 million (500 million HUF). The cost of a PAD should be no more than $0.35 \%$ of the overall construction budget, and it should contain the following elements (if possible):

- collection of previous data on the site (provided by the local museums)

- field survey

- geophysical survey

- trial excavation

Based on these data a project plan is made giving an estimated cost and timescale for archaeological works. Without a PAD the development would not receive a building permit. A PAD still has to be prepared even if the construction area does not have any known archaeology. PADs are submitted to the District Heritage Office, Heritage Registry Office of the Prime Minister's Office, Hungarian National Museum and county museum.

After the excavation further documents have to be submitted called the 30-day report and 1-year report, and the submission of this primary excavation documentation is also regulated. By law these documents also have to be submitted to the District Heritage Office, Heritage Registry Office of the Prime Minister's Office, Hungarian National 
Museum, county museum and to a museum where the finds are stored. (In some cases an excavation is not carried out by the local museum, but if the finds will be stored there eventually the local museum also receives a copy of the abovementioned documentation) (27/4§ of the 68/2018 (IV.9) Government Decree).

In light of the above, the main documents of preliminary surveys (PADs) and excavations (the 30-day and 1-year report) are submitted to centralised institutions, in theory facilitating their digital archiving and accessibility. However, further documents (inventories, databases, scientific assessment, interdisciplinary analysis, photos, drawings, etc.), which are mainly created in the museum that carried out the excavation or in the museum where the material is finally stored, may not end up in the designated repositories. Instead, these documents are stored in the local museums that carried out the excavations and/or where the finds are kept. In other words, there is no officially appointed centralised hard copy and/or digital repository in Hungary where all the site documents are stored and made accessible. In this respect, there are millions of files stored in museums all over the country that are neither used nor reused and are not accessible, and without the archaeological community, or even central institutions, being aware of them.

In this system only some of the documents (PAD, 30-day and 1-year reports) are available and accessible in the central institutions to which this primary documentation has to be submitted. In this way, the site documents live completely separate lives and local museums are the only places where all the documents are kept together (and even here access is very restricted, with permission needed from the leader of the excavation).

A major problem is that digital archiving of archaeological documents is not regulated either on a national or on a local level, and only guidance exists (Kómár and Bánki 2019). Therefore, digital data are often archived as objects rather than as computerised information. It is entirely up to the individual museums how they store or archive digital data and provide access to them. Even if digital data are archived, the archiving process does not follow any particular local or national protocol. This is a major drawback not only in terms of the FAIR principles but in terms of archiving and long-term preservation as well.

Concerning repositories with digital heritage data, the Heritage Registry Office of the Prime Minister's Office operates a public register (not publicly accessible), in which, in theory, all new metadata on archaeological sites are included. This register contains only metadata about the sites and about those documents that have to be submitted by law (see above). Nevertheless, documents are not included in the public register. Moreover, metadata are not included for additional documents, for example concerning interdisciplinary analyses or restoration etc., since central institutions have no knowledge of the existence of these further documents. Again, the information is partial and local museums are the only places where all metadata and documents are available. 


\section{The Hungarian Archaeology Database}

The only repository that includes both metadata and documents in Hungary is the Archaeology Database of the National Museum. In Hungary there has been an increasing need to provide archaeologists with an accessible online catalogue of archaeological sites, including site metadata and documentation. Open access to archaeological data is still in its infancy in Hungary, but ARIADNE and ARIADNEplus respectively made it possible for the National Museum to develop an archaeology database and continuously mobilise more and more archaeological data (Kreiter 2019). The archaeology database provides a solution for depositing digital documents and it can serve as a national repository where documents can be stored and accessed online in one place (through access levels). Nevertheless, submitting digital documents to the archaeology database is unregulated; it is completely voluntary, although more and more researchers provide their site documentation to the database.

As discussed earlier the submission of some of the documents (PAD, 30-day and 1-year report) is regulated and by law these documents have to be submitted to several institutions. Their format (content, structure, file/folder naming conventions) is described by protocols. This should assist archiving on a national level should it become compulsory to submit them to the archaeology database, as its structure was designed in accordance with the protocols and it hosts documents.

Concerning the accessibility of data, the archaeology database has different access levels. Non-professionals (public) can access short reports of sites published in the volumes of Archaeological Investigations in Hungary but no other documents or spatial information on sites are accessible to the public.

Professionals may have full access to the database including access to all uploaded documents and data on sites. The purpose of the archaeology database of the National Museum is to support research, teaching and learning and, in this respect, accessibility is almost FAIR since data and documents are findable, accessible and reusable but only by professionals. However, it is a major drawback that submission is not mandatory and therefore information is partial. Interoperability of metadata is realised since the data model, descriptive concepts, terms and temporal coverage of archaeological sites became standardised (Aloia et al. 2017). Interoperability of documents is restricted, since the structure and contents of the documents follow country-specific regulations.

In order to involve archaeologists and museums, and to facilitate an increase in the quality and quantity of metadata and site documents, there is a function in the database through which professionals can comment on or add metadata to any site in the database (in a controlled way). In this way the quality of data continuously improves, and since the launch of the database in May 2016 thousands of items of metadata have been corrected or added to sites. Moreover, there is a feature through which archaeologists can upload sites to the database and send documentation to be uploaded.

Even though submitting digital documents to the archaeology database is voluntary, more and more professionals are providing documents. This is an important sign of a 
paradigm shift in the Hungarian archaeology community. There is virtually no size limit for documents to be uploaded to the database and amounts of data that would be unpublishable can be stored in one place, and accessibility (through access levels), archiving and long-term preservation is also assured. The database was developed with a long-term plan in mind - to serve as a national repository for archaeological data and documentation. The Archaeology Database indeed provides a solution for keeping data and documentation in one system and can serve as a repository for other Hungarian museums as well. We encourage Hungarian archaeologists and museums to join this unprecedented endeavour to assess our national heritage and make it accessible to the research community via the Archaeology Database of the National Museum.

The main benefits of the Hungarian Archaeology Database can be summarised as follows:

- Archaeological sites are protected since sensitive data can only be accessed by professionals.

- Where available, all documents are presented together for a site (from 30-day report to interdisciplinary results). Each site has a unique URL for referencing.

- Unpublishable amounts of documentation can be uploaded for each site; there is virtually no size limit. Archiving and long-term preservation is also assured.

- The database is updated regularly with new and controlled data. Professionals can also modify site data (via a controlled process), improving data quality.

Detailed search functions allow assessment of available data and/or the planning of regional/national scientific projects.

- Sites involved in a research project can be linked together and the results can be visualised/demonstrated in the database and all the results and documentation can be accessed in a controlled manner, showing funding bodies the results of a research project.

- Online available information on the quantity and quality of the assemblages speeds up research, saves time and resources, and also speeds up the process of working with legacy sites, mobilising their data and increasing scientific exploitation.

- Hungarian professionals and museums can join the database and upload sites and documentation using a controlled process.

\section{Conclusion}

In conclusion, there is a strong need for a national digital archive for archaeological documents and the only way to move forward and promote the Archaeology Database is to mandate the submission of metadata and digital documents to the database at a national level, including all documents emerging through the assessment of the site and finds. 
Aloia, N., Binding, C., Cuy, S., Doerr, M., Fanini, B., Felicetti, A., Finn, J., Gavrilis, D., Geser, G., Hollander, H., Meghini, C., Niccolucci, F., Nurra, F., Papatheodorou, C., Richards, J., Ronzino, P., Scopigno, R., Theodoridou, M., Tudhope, D., Vlachidis, A. and Wright, H. 2017 'Enabling European archaeological research: the ARIADNE EInfrastructure', Internet Archaeology 43. https://doi.org/10.11141/ia.43.11

Kómár, É. and Bánki, Zs. 2019 Fehér könyv. Módszertani útmutató a közgyüjteményi kulturális örökség digitalizálásához és közzétételéhez. Budapest, Emberi Erőforrások Minisztériuma. http://www.oszk.hu/kds-k/feher-konyv

Kreiter, A. 2019 'The Hungarian archaeology database in the light of ARIADNE' in J.D. Richards and F. Niccolucci (eds) The ARIADNE Impact, Budapest: Archaeolingua. 638. https://doi.org/10.5281/zenodo.3476712 